\title{
XXXIX. Some further experiments on the circulation of the residual gaseous matter in crookes tubes
}

\section{Alan A. Campbell Swinton}

To cite this article: Alan A. Campbell Swinton (1898) XXXIX. Some further experiments on the circulation of the residual gaseous matter in crookes tubes, Philosophical Magazine Series 5, 46:281, 393-395, DOI: $10.1080 / 14786449808621209$

To link to this article: http://dx.doi.org/10.1080/14786449808621209

曲 Published online: 08 May 2009.

Submit your article to this journal $\pi$

Џll Article views: 2

Q View related articles $\longleftarrow$ 
wheel in the forward position and the other with its wheel in the back position. The two tubes can be operated simultaneously by connecting them in series.

It should also be stated that for these experiments extremely high vacua are requisite, and that with a Ruhmkorff' coil as the source of electrical power the effects can only be shown satisfactorily with the tube connected to the mercury-pump, for the reason that the discharges from the coil inevitably bring down the vacuum very quickly, apparently by their action upon the mica vanes, which are visibly affected when the cathode-stream from the concave cup is allowed to fall upon them. Using a small Wimshurst machine, however, the effects can be shown after the tube has been senled off, though eren then with use the vacuum appears to deteriorate in a short time.

XXXIX. Some Further Euperiments on the Circulation of the Residual Gaseous Matter in Crookes Tubes. By ALAN A. Campbell Swinton *.

T $N$ the discussion which followed my former paper on this 1 subject some objection was taken to the use of a nonconducting substance, i. e. mica, for the vanes of the mill which was used to detect the circulation of the ultra-gaseous matter, it being suggested by Professor Boys that the rotation produced might be the result of electrification of the ranes. It was further suggested by Mr. Appleyard that gilding the vanes, so as to make them conductive, might modify the effect.

Mr. Wolff has now constructed for me a tube similar to fig. 1 of my former paper, but with the mica vanes gilded and mounted on a brass cap revolving upon a steel needle-point connected with a wire and terminal, so that the vanes can readily be earthed.

In this condition, and with the ranes so placed as to be outside the cathode-stream, it is found that this wheel behaves in a similar manner to the former non-conducting and insulated wheel. It shows a greater tendency to assume a position of stability, due evidently to electrostatic induction; but though this renders it sometimes rather troublesome in starting, still when once under weigh it will continte to rotate as long as the tube is excited. It will occasionally, when starting, make a few reverse revolutions, due probably to electrostatic influence and momentum, and also possibly to eddy-currents

* Communicated by the Physical Society: read May 27, 1898 . 
in the residual gaseous matter; but it is found that when it does this it invariably reverses its rotation almost immediately, and proceeds to rotate more and more rapidly in the direction that indicates a stream of residual gaseous matter passing from the anode to the cathode. Usually, after one or two oscillations, it starts immediately to rotate in this direction.

An electrometer connected to the wheel through the pivot and needle-point shows that the vanes are always positively electrified.

In order further to investigate the matter, I have had constructed another form of radiometer-tube, as shown in the accompanying illustration. Here the vanes (of mica) are

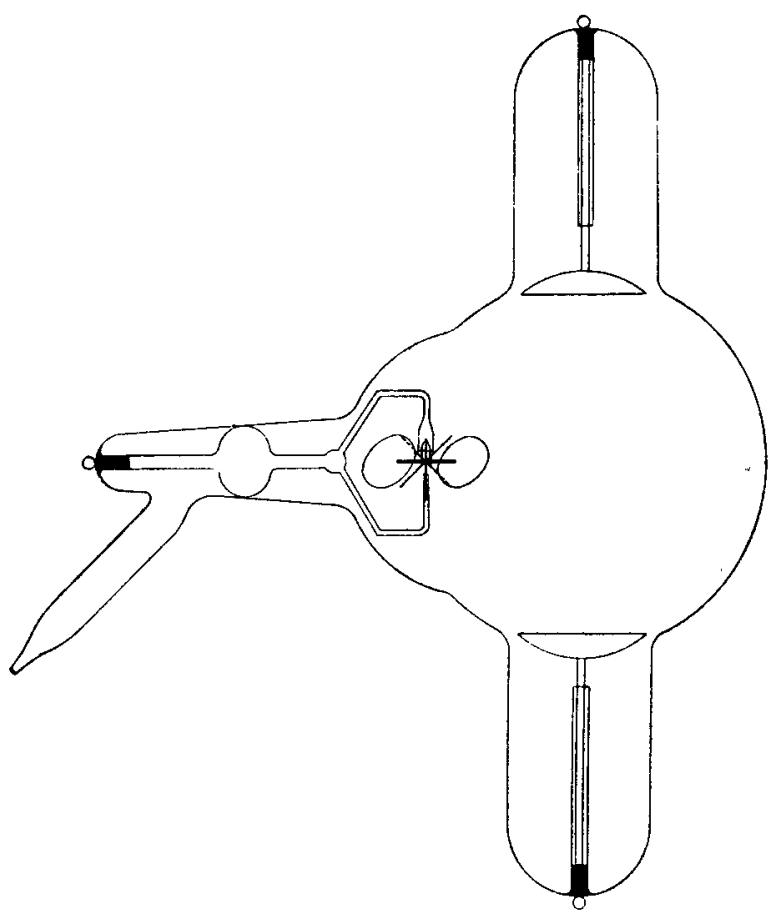

inclined, and the axis is parallel to the line joining the cathode and anode. The wheel thus rotates in a plane at right angles to the cathode- and anode-streams ; and it is difficult to see how electrification of the vanes should in any way assist its rotation either in one direction or in another.

The wheel is arranged so that the vanes are all outside the cathode-stream, and when the tube is excited it is found inva- 
riably to rotate in a direction indicating a stream from anode to cathode. Concave aluminium cups are used for both electrodes, and the direction of rotation of the wheel is found immediately to reverse when the positive and negative connexions are transposed.

These experiments consequently confirm the hypothesis suggested in my former paper, that at very high exhaustions there exists a molecular or atomic stream from anode to cathode which carries a positive charge and travels at considerable velocity outside of the opposite cathode-stream.

XL. On the Possille Effects of Solur Magnetization on Periodic Variations of Temestral Magnetism. By ArThur SCHUTTER, F.R.S."

1. TN the rarious attempts which have been made to 1 establish a periodicity in the elements of terrestrial magnetism, depending on solar rotation, it has been uniformly assumed that the periodic time is that of the synodic revolution of the sun. This seems plausible at first sight, but on closer investigation it is found not to be true.

There are two principal periods which might be caused by a transversely magnetized sun, one being of about 25 days and equal to the time of sidereal revolution, while the other, and more important, bas a time of $29 \cdot 1$ days, being longer than the synodical revolution by about as much as that is longer than the sidereal revolution.

Minor periods are produced by the eccentricity of the earth's orbit, and among these one has a time equal to that of the synodical revolution. But as the amplitude of this period amounts only to about the thousandth part of the amplitude of the principal period, it may for all practical purposes be neglected.

If it can be proved, therefore, that the elements of terrestrial magnetism have a period equal to that of the synodic revolution of the sun, while the sidereal period is absent, it would follow that this cannot be due to a direct effect of solar magnetization. At present, however, the so-called 26-day period rests on a feeble and altogether insufficient hasis, which is still furtber weakened by the absence of any rera causa for the period.

The reason why the solar revolution does not produce the effect which is commonly ascribed to it, lies in the fact that

$$
\text { * Communicated by the Author. }
$$

